\title{
Epithelioid trophoblastic tumor: clinicopathological features with an emphasis on uterine cervical involvement
}

\author{
Oluwole Fadare ${ }^{1}$, Vinita Parkash ${ }^{2}$, Maria-Luisa Carcangiu ${ }^{3}$ and Pei Hui ${ }^{1}$ \\ ${ }^{1}$ Department of Pathology, Yale University School of Medicine, New Haven, CT, USA; ${ }^{2}$ Department \\ of Pathology, Hospital of Saint Raphael, New Haven, CT, USA and ${ }^{3}$ Department of Pathology, Istituto \\ Nazionale Tumori, Milan, Italy
}

\begin{abstract}
We report on the clinical and histological features of five cases of epithelioid trophoblastic tumor, with an emphasis on its involvement of the uterine cervix. All five patients were of reproductive age (median age 38.4 years) and all, except one, presented with vaginal bleeding 3 to 18 years after the most recent pregnancy. One patient presented with amenorrhea. Elevation of serum human chorionic gonadotropin (hCG) was seen in four cases. Pathologically, the tumor involved endocervix in three cases and involved uterine corpus in another two. All five tumors were invasive, nodular lesions consisting of epithelioid intermediate trophoblastic cells that were mononuclear with abundant eosinophilic cytoplasm, along with zones of hyaline material and necrotic debris. In three cases of cervical involvement, the neoplastic cells focally replaced endocervical surface and glandular epithelium, simulating high-grade squamous intraepithelial lesions. Immunohistochemically, all five tumors displayed focal positivity for human placental lactogen and hCG. Positive nuclear staining of p63 was seen in all five cases. All patients received total hysterectomy and various regimes of adjuvant chemotherapy. Three patients survived the tumor with no recurrences or metastases with follow-up periods of 3, 7 and 16 years. One patient is currently alive with lung metastasis 1 month after the surgery. One patient died of tumor metastasis $\mathbf{8}$ months after the diagnosis. In summary, with its unusual ability to simulate an invasive squamous cell carcinoma and other epithelioid neoplasms, epithelioid trophoblastic tumor frequently poses a diagnostic challenge, especially when involving the uterine cervix. High index of suspicion and an awareness of elevation of serum chorionic gonadotropin are crucial in reaching a correct diagnosis.
\end{abstract}

Modern Pathology (2006) 19, 75-82. doi:10.1038/modpathol.3800485; published online 23 September 2005

Keywords: epithelioid trophoblastic tumor; cervix; pathology

Epithelioid trophoblastic tumor is a rare neoplasm and represents the most recent addition to the gestational trophoblastic tumor category. ${ }^{1}$ Most of the patients reported in the literature were of reproductive age women, and the antecedent gestational events had varied significantly, including fullterm deliveries, spontaneous abortions and molar gestations. ${ }^{2-4}$ The average interval between the antecedent gestation and the development of the tumor is 6.2 years. The patients generally present with vaginal bleeding and low-level elevation of serum human chorionic gonadotropin (hCG). Although most cases of epithelioid trophoblastic tumor have

Correspondence: Dr P Hui, MD, PhD, Department of Pathology, Yale University School of Medicine, BML 250, 310 Cedar Street, New Haven, CT 06520-8023, USA.

E-mail: pei.hui@yale.edu

Received 23 May 2005; revised 27 July 2005; accepted 1 August 2005; published online 23 September 2005 a favorable outcome, metastases and death occur in 25 and $10 \%$ of the patients, respectively. ${ }^{4}$ Before the recognition of the tumor in late 1990s, the tumor was variously diagnosed as atypical choriocarcinoma, placental site trophoblastic tumor and squamous cell carcinoma. In contrast to other forms of gestational trophoblastic diseases, approximately $50 \%$ of reported epithelioid trophoblastic tumors arose from the uterine cervix or lower uterine segment. ${ }^{2}$ Histologically, epithelioid trophoblastic tumor is a distinct neoplasm whose cytological features and growth patterns mimic squamous cell carcinoma. As squamous cell carcinoma and its associated intraepithelial lesions are the most common lesions of the uterine cervix, epithelioid trophoblastic tumor can pose a significant diagnostic challenge to routine surgical pathology practice. Herein, we report the clinical and histological findings of five examples of this condition with an emphasis on the pathological features when the tumor involves the uterine cervix. 


\section{Materials and methods}

\section{Case Selection}

Three cases of epithelioid trophoblastic tumor was identified in Yale Pathology files, one case was obtained from Memorial Sloan-Kettering Cancer Center and one case was identified recently at the Istituto Nazionale Tumori, Milan, Italy. Complete medical record reviews were performed in all five cases (Table 1). Four patients were initially evaluated by either cervical or endometrial samplings and one patient by laparoscopic biopsies of pelvic organs. All patient eventually underwent abdominal hysterectomy. Three patients received staging procedures including bilateral salpingoophorectomy, pelvic lymph node sampling and peritoneal washing. Two patients received simple hysterectomy. Various regimes of adjuvant chemotherapy were given to all patients. Two of the Yale cases were interpreted as cervical carcinoma in their initial biopsies, but eventually recognized as trophoblastic tumors due to their unusual clinical behavior and subsequent immunohistochemical studies. One case was diagnosed as epithelioid malignant mesothelioma upon pelvic biopsies. Two other cases were initially interpreted as placental site trophoblastic tumors, but were reviewed and eventually recognized as epithelioid trophoblastic tumors according to the published criteria and follow-up immunohistochemical studies.

\section{Histopathology and immunohistochemistry}

All tissue specimens were subjected to standard macroscopic and histological examinations. Tissue sections were processed routinely for morphologic assessment: sections were fixed in 10\% neutral- buffered formalin, processed, embedded in paraffin, sectioned and stained with hematoxylin and eosin. For immunohistochemistry, $4 \mu \mathrm{m}$-thick, formalinfixed, deparaffinized sections were stained with a panel of antibodies using a DAKO Autostainer (DakoCytomation, Carpinteria, CA, USA) based on the avidin-biotin-peroxidase complex. Immunomarkers in this study included cytokeratin (AE1/3, dilution 1:1200; DakoCytomation), human placental lactogen (hPL, 1:5000; DakoCytomation), betahuman chorionic gonadotropin ( $\beta$-hCG, 1:2000; DakoCytomation) and P63 (4A4, dilution 1:100; Neomarker).

\section{Results}

\section{Clinical Case History}

\section{Case 1}

In 1987, a 44-year-old gravida 1 para 1 presented to her primary physician with complaints of vaginal bleeding. A pelvic examination revealed a polypoid lesion in the cervical area and was biopsied. The biopsy was interpreted as poorly differentiated carcinoma, although unusual morphologic features were noted. These included large areas of hyalinized material that was believed to be basement membrane material. Cells suggestive of trophoblasts were also identified, but stains for hCG were negative in the biopsy. The patient's antecedant gestation was a normal vaginal delivery of a female fetus 18 years previously. Serum $\beta$-hCG measurements were not taken. The patient subsequently underwent a type III radical hysterectomy and bilateral salpingoophorectomy with bilateral deep pelvic and para-aortic lymph node sampling. She further received external

Table 1 Clinicopathologic characteristics of five cases of epithelioid trophoblastic tumor

\begin{tabular}{|c|c|c|c|c|c|}
\hline Clinicopathologic parameters & Patient 1 & Patient 2 & Patient 3 & Patient 4 & Patient 5 \\
\hline Patient age (years) & 44 & 42 & 29 & 35 & 42 \\
\hline Presentation & Vaginal bleeding & Menormetrorrhagia & Unavailable & Menormetrorrhagia & $\begin{array}{l}\text { Amenorrhea/ovarian } \\
\text { enlargement }\end{array}$ \\
\hline Prehysterectomy diagnosis & $\begin{array}{l}\text { Poorly } \\
\text { differentiated } \\
\text { carcinoma }\end{array}$ & $\begin{array}{l}\text { Moderately } \\
\text { differentiated } \\
\text { carcinoma }\end{array}$ & PSTT & None & $\begin{array}{l}\text { Epithelioid } \\
\text { mesothelioma of } \\
\text { peritoneum }\end{array}$ \\
\hline Hysterectomy diagnosis & $\begin{array}{l}\text { Adenosquamous } \\
\text { carcinoma }\end{array}$ & $\begin{array}{l}\text { Poorly differentiated } \\
\text { trophoblastic tumor }\end{array}$ & PSTT & $\begin{array}{l}\text { PSTT with } \\
\text { epithelioid features }\end{array}$ & $\begin{array}{l}\text { Epithelioid } \\
\text { trophoblastic tumor }\end{array}$ \\
\hline Year of initial diagnosis & 1987 & 1997 & 1991 & 2000 & 2004 \\
\hline Tumor size (cm) & 4.0 & 2.5 & 2.4 & 4.0 & 3.0 \\
\hline Anatomic location & Endocervix & $\begin{array}{l}\text { Endocervix and lower } \\
\text { uterine segment }\end{array}$ & $\begin{array}{l}\text { Uterine corpus } \\
\text { (intracavitary } \\
\text { and } \\
\text { myometrial) }\end{array}$ & $\begin{array}{l}\text { Uterine corpus } \\
\text { (outer myometrial) }\end{array}$ & $\begin{array}{l}\text { Endocervix and } \\
\text { uterine isthmus }\end{array}$ \\
\hline Tumor necrosis & $30 \%$ & $5 \%$ & $10 \%$ & $50 \%$ & $>50 \%$ \\
\hline Mitosis/10 HPF & 2 & 9 & 48 & 2 & 3 \\
\hline Ki-67 index (\%) & 10 & 30 & 86 & 50 & N/D \\
\hline Follow-up & NERM at 16 years & NERM at 7 years & $\begin{array}{l}\text { Died of disease } \\
8 \text { months after } \\
\text { surgery }\end{array}$ & NERM at 3.25 years & $\begin{array}{l}\text { Alive with lung } \\
\text { metastasis } 1 \text { month } \\
\text { after surgery }\end{array}$ \\
\hline
\end{tabular}

$\mathrm{PSTT}=$ placental site trophoblastic tumor; $\mathrm{NERM}=$ no evidence of tumor recurrence or metastases; HPF $=$ high-power field; $\mathrm{N} / \mathrm{D}=$ not done. 
whole pelvic radiotherapy (4500 rads) with an additional right parametrial boost (540 rads). She also received gamma-med irradiation to the vaginal cuff and 12 cycles of methotrexate, $5 \mathrm{FU}$ and leukovorin. A postoperative diagnostic work-up for extrauterine disease was negative. She has been followed clinically by biannual cervicovaginal smears without evidence of tumor metastases or recurrence 16 years after completion of treatment.

\section{Case 2}

Patient 2 is a 42-year-old gravida 4 para 3 (three normal spontaneous vaginal deliveries and one spontaneous abortion) who presented to her primary physician in 1997 with a 3 year history of irregular bleeding that had increased significantly over the previous 3 months. Her most recent gestation resulted in a spontaneous abortion 10 years previously. Serum hCG was measured at $5494 \mathrm{mIU} / \mathrm{ml}$. An endometrial biopsy and pap smear were simultaneously performed and both showed atypical cells whose nature could not be determined definitively. She subsequently underwent a cone biopsy of the cervix and an invasive epithelioid neoplasm was found. Although the tumor showed rare individual cell immunopositivity for $\beta$-hCG and hPL, the case was diagnosed as a moderately differentiated carcinoma. The patient subsequently underwent a total abdominal hysterectomy and bilateral salpingoophorectomy in which a poorly differentiated trophoblastic tumor with epithelioid features was diagnosed to involve the upper portion of endocervical canal and lower uterine segment. The patient received adjuvant combination chemotherapy that consisted of bleomycin, VP16 and cisplatin. At 1 month after her surgery, her serum hCG had declined to $2.7 \mathrm{mIU} / \mathrm{ml}$. A postoperative work-up for extrauterine disease only revealed an anterior mediastinal mass, which was eventually sampled and found to be a benign thymoma. She has been followed clinically by biannual cervicovaginal smears without evidence of tumor metastases or recurrence 7 years after completion of treatment.

\section{Case 3}

The third patient, a 29-year-old gravida 2 para 2, was diagnosed with a uterine tumor that was believed at the time to represent a placental site trophoblastic tumor. Information on her precise clinical presentation is not available. Antecedent gestational events included two-term deliveries 10 and 3 years previously. At 1 year prior to the current presentation, she had a positive pregnancy test and was subsequently thought to have had a spontaneous abortion. However, a progressive increase in serum hCG levels (maximum level $2400 \mathrm{mIU} / \mathrm{ml}$ ) was noted afterward. Her initial diagnosis of placental site trophoblastic tumor was rendered on the material obtained from uterine fractional dilatation and curettage and a laparoscopic peritoneal biopsy, both of which were involved by the tumor. She subsequently underwent a hysterectomy. Immediately after her surgery, she was placed on a variety of chemotherapeutic regimens. She however developed bilateral pulmonary metastatic disease 8 months after her surgical procedure and died shortly thereafter.

\section{Case 4}

A 35-year-old nulligravid female presented to her physician with complaints of heavy menstrual bleeding for the previous 10 days. A urine pregnancy test was negative, but serum hCG was measured at $300 \mathrm{mIU} / \mathrm{ml}$. She was investigated for a possible ectopic gestation, but none was found. Endometrial curettage showed no pathologic changes. A pelvic ultrasound showed a circumscribed mass in the anterolateral mid-portion of the uterus, which was interpreted as a degenerating leiomyoma. Computed tomographic (CT) scans of the chest and pelvis were otherwise normal. Several weeks after the presentation, her serum hCG had raised to $635 \mathrm{mIU} / \mathrm{ml}$, and on the presumption of an 'occult' gestational trophoblastic disease, she was placed on methotrexate. Over the next 5 months, her serum hCG levels oscillated but progressively rose, attaining a peak of $2025 \mathrm{mIU} / \mathrm{ml}$. During this 5month period, she received two doses of methotrexate alternated with leukovorin. Since the uterine lesion was the only identifiable pathology, she underwent a simple hysterectomy, followed by adjuvant chemotherapy with methotrexate, etoposide (VP16) and leukovorin. At 5 weeks after her surgery, her serum hCG was undetectable. She has been followed by biannual cervicovaginal smears without evidence of tumor metastases or recurrence 3.25 years after completion of treatment.

\section{Case 5}

A 42-year-old gravida 2 para 2 presented to her gynecologist with amenorrhea in December 2004. Her last pregnancy was at age 29 years. Transvaginal ultrasound showed enlargement of the right ovary, which was interpreted as probable dermoid cyst. Her serum hCG was $200 \mathrm{mIU} / \mathrm{ml}$. She received laparoscopy examination, which revealed a $9 \mathrm{~cm}$ round thick-walled cystic mass attached to the right vesicouterine fold and a nodule on the bladder wall. Biopsies from both lesions were interpreted by the local pathologist as epithelioid mesothelioma. A right cystectomy of the ovary was also performed and a dermoid cyst of the right ovary was diagnosed. In January 2005, CT scan showed multiple bilateral (few $\mathrm{mm}$ in size) lung nodules. The patient was admitted to the Istituto Nazionale Tumori, Milan and exploratory laparotomy was performed. On the right parametrial region, a thick-walled cystic mass was seen and interpreted as an abscess by the surgeon. Biopsies from the 'abscess' wall and the 
peritoneum were taken and the diagnosis of epithelioid trophoblastic tumour was eventually made. Her follow-up hCG was $3358 \mathrm{mIU} / \mathrm{ml}$ in March 2005 and she then received three cycles of EMA-CO chemotherapy (etoposide, high-dose methotrexate with folinic acid, actinomycin D, cyclophosphamide and vincristine). Her hCG once increased to $5900 \mathrm{mIU} / \mathrm{ml}$ in April, then went down to $39.7 \mathrm{mIU} /$ $\mathrm{ml}$ in May 2005. The patient received radical hysterectomy and salpingoophorectomy with lymph node dissection in June 2005. Her hCG was $14.4 \mathrm{mIU} / \mathrm{ml}$ at the time of the surgery. Her postsurgery hCG was $1.7 \mathrm{mlU} / \mathrm{ml}$. The patient is currently having other three cycles of EMA-CO regimen of chemotherapy.

\section{Pathological and Immunohistochemical Findings}

\section{Gross pathological findings}

In case 1, a $4.0 \mathrm{~cm}$ circumferential, yellowish, fungating tumor involved the endocervix with a maximal depth invasion of $3.5 \mathrm{~cm}$. Case 2 showed a well-defined nodular, fleshy and solid mass measuring $2.5 \mathrm{~cm}$ at the junction of endocervix and lower uterine segment (Figure 1). The tumor grossly invaded $95 \%$ of the endocervical wall. The tumor mass in the third case was a firm and hemorrhagic intracavitary and myometrial lesion with a measurement of $2.4 \mathrm{~cm}$. The tumor in case 4 was a tanyellow, friable mass, which measured $4.0 \mathrm{~cm}$ within the anterior myometrium, $0.6 \mathrm{~cm}$ in distance to the

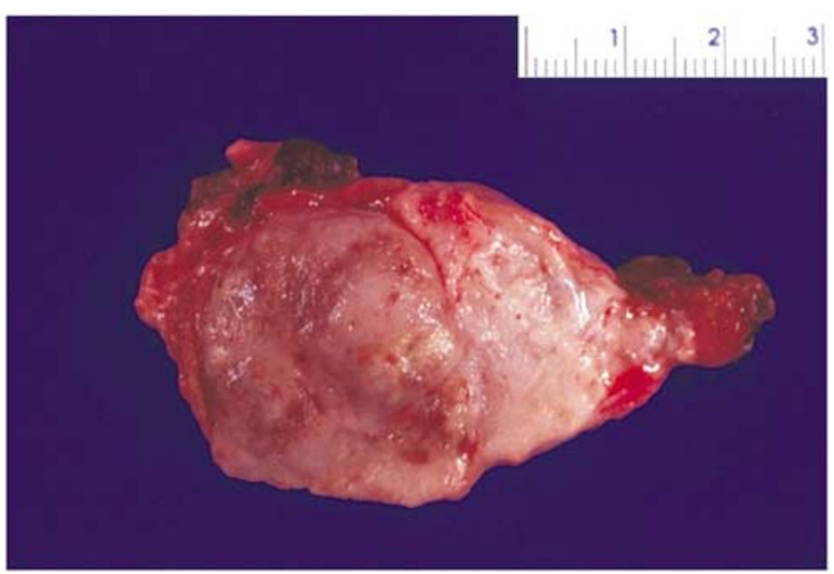

Figure 1 Gross photograph of a $2.5 \mathrm{~cm}$ epithelioid trophoblastic tumor (case 2, cross-section) involving the upper endocervix. The tumor is an expansile mass with fleshy, solid appearance on cut surface and invades underlying stroma. endometrial surface and less than $0.1 \mathrm{~cm}$ from the serosal surface. In case 5 , the hysterectomy specimen revealed a round ulcerated mass involving upper cervix and uterine isthmus with fistulous tract formation through the isthmus $(2.5 \mathrm{~cm}$ in maximum diameter). The tumor was $3.0 \mathrm{~cm}$ in size and was partially necrotic with areas of hemorrhage, grossly infiltrating the entire thickness of the uterine isthmus and upper third of the cervix.

\section{Microscopic findings}

The tumors in all five cases showed microscopic features that have been described for epithelioid trophoblastic tumor. ${ }^{2,5}$ The tumors were invasive, nodular lesions consisting of mononuclear epithelioid intermediate trophoblastic cells with abundant eosinophilic or clear cytoplasm and medium to large, irregular nuclei with distinct nucleoli. Scattered multinucleated cells were also present. In the center of tumor nests, there was often an area of hyalinization or eosinophilic debris of tumor cell necrosis, resembling keratinous material in a squamous cell carcinoma (Figure 2a-c). Areas of such changes ranged from 3 to $50 \%$ (Table 1). At the periphery, the tumor cells often form small round nests or cords infiltrating surround normal tissue (Figure 2d). In three cases of cervical involvement, the neoplastic cells focally replaced endocervical epithelium and glands with stratified neoplastic cells, simulating high-grade squamous intraepithelial lesions (Figure 2e), in addition to the underlying invasive tumor mass. Mitosis was present in all five tumors, ranging from 2 to 48 per 10 high-power fields (Table 1). Aggregates of decidualized stromal cells were present in the adjacent neighborhood in two cases that involved the cervix (Figure 2f). Focal parametrial involvement and lymphovascular invasion by the tumor was seen in one case (case 1). Two patients who received staging procedures did not show any lymph node or distant tumor metastasis. One patient showed tumor spreading onto surfaces of bladder and uterus.

\section{Immunohistochemical Findings}

The tumors in all five cases were positive for $\beta$-hCG and/or hPL in a focal, individual cell pattern (Figure 2g). Cytokeratin AE1/3, when applied, was strongly positive. P63 was diffusely positive in all cases in a nuclear staining pattern (Figure 2h). Proliferating index ranged from 10 to $86 \%$ based on immunostaining of Ki-67.

Figure 2 Histological and immunohistochemical features of epithelioid trophoblastic tumor. (a) Nodular expansile mass lesion at low magnification $(\mathrm{HE} \times 4)$. $(\mathbf{b}$ and $\mathbf{c})$ Medium $(\mathrm{HE} \times 10)$ and high $(\mathrm{HE} \times 40)$ magnifications of the tumor showing epithelioid intermediate trophoblastic tumor cells and eosinophilic hyalinization (keratin-like material) within tumor nests, simulating invasive squamous cell carcinoma. (d) Tumor cells forming small nests and cords at the periphery of the tumor $(\mathrm{HE} \times 20)$. (e) Focal replacement of endocervical glandular epithelium to mimic high-grade squamous intraepithelial lesion (HE $\times 40)$. (f) Aggregates of decidualized stromal cells (upper area) adjacent to tumor nests (lower middle area) (HE $\times 20)$. (g) Focal individual cell positivity for human placental lactogen (hPL) and (h) diffuse nuclear immunostaining for p63. 

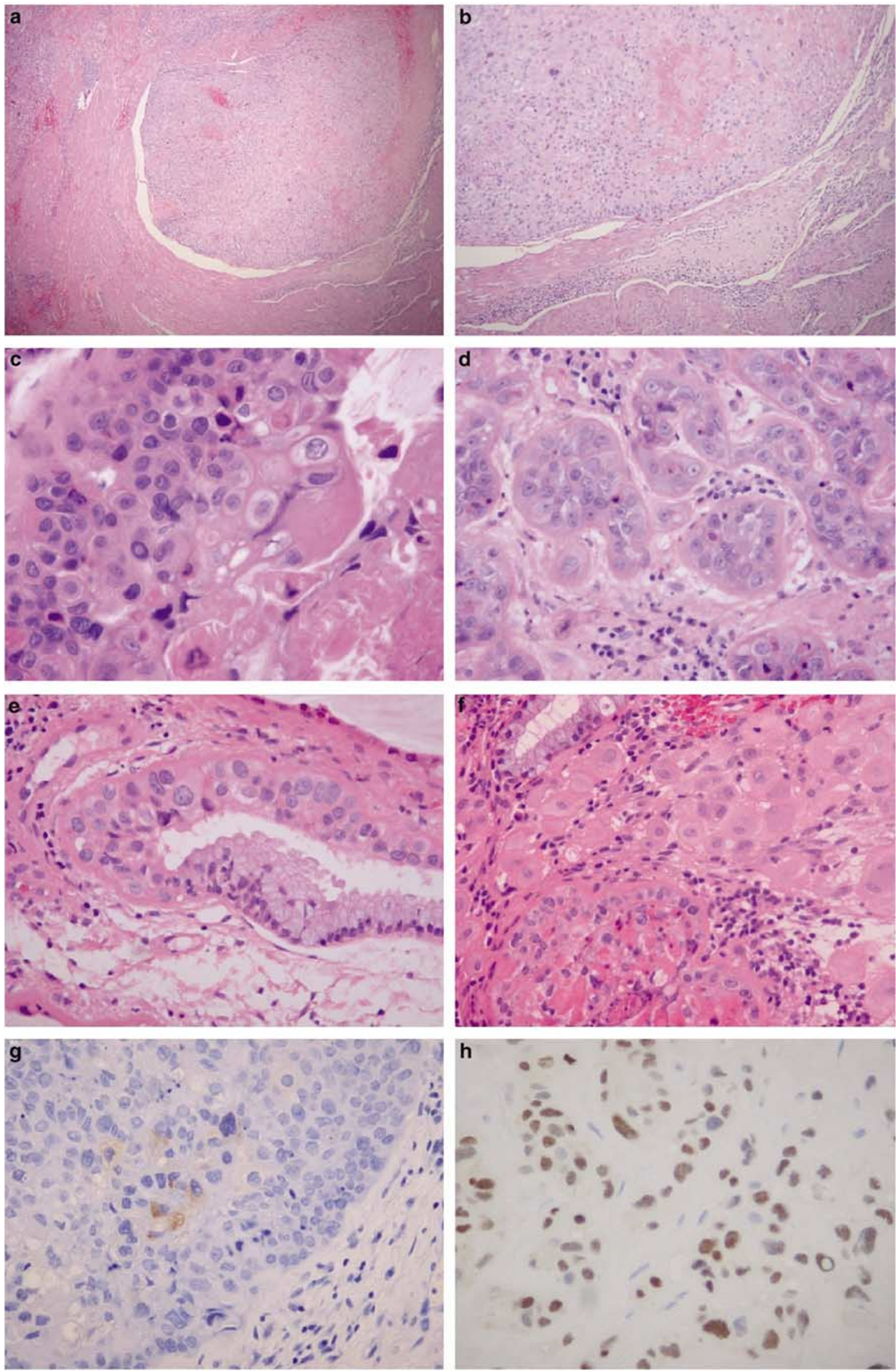


\section{Discussion}

The term 'epithelioid trophoblastic tumor' was originally introduced by Mazur and Kurman in $1994,{ }^{5}$ although similar tumors were reported earlier by Silva et $a l^{6}$ as 'multiple nodules of intermediate trophoblast' of the uterus. In 1998, Shih and Kurman $^{2}$ outlined the clinicopathologic characteristics of epithelioid trophoblastic tumor in 14 patients, and therefore established epithelioid trophoblastic tumor as a distinct entity within the category of gestational trophoblastic tumors. Since then, approximately 90 cases have been reported in the literature..$^{2-3,7-19}$ Histopathologically, the most challenging differential diagnosis is to separate the tumor from an invasive squamous cell carcinoma, particularly when it arises in the cervix or lower uterine segment. The fact that, in approximately half of the reported cases, the tumors developed at the endocervix and lower uterine segment ${ }^{2}$ renders such a differential diagnosis as the most frequently encountered one. Epithelioid trophoblastic tumor displays a nodular proliferation of monomorphic population of intermediate-sized epithelioid trophoblasts with eosinophilic or clear cytoplasm, forming nests and cords. In the center of tumor nests, there is often an area of hyalinization or eosinophilic debris, resembling keratinous material in a squamous cell carcinoma. The most unusual feature of epithelioid trophoblastic tumor that occurs in the cervix is the focal replacement of the surface and/or glandular epithelium with stratified neoplastic cells, simulating squamous intraepithelial neoplasia. All these pathological features of epithelioid trophoblastic tumor can mislead to an incorrect diagnosis as squamous cell carcinoma. This has been illustrated by two cases in this study, in which the initial interpretations were invasive carcinomas of the cervix. Table 2 summarizes key features in separating a squamous cell carcinoma from an epithelioid trophoblastic tumor. High index of suspicion and typical clinical presentation in a young woman having relatively low, but definitely elevated level of serum hCG $(<2500 \mathrm{mIU} / \mathrm{ml})$ and/or intrauterine mass by ultrasound are important to make a correct diagnosis. Histologically, the absence of definite squamous intraepithelial lesion, the presence of decidualized stromal cells in the neighborhood, positive immunostaining for inhibin- $\alpha$, hPL and cytokeratin 18 (CK18) are features that help to confirm a diagnosis of epithelioid trophoblastic tumor. ${ }^{3,19}$ Anti-HLA-G is a recently introduced, and commercially available antibody that is specific to trophoblastic cells and appears of great value in this differential diagnosis as well. ${ }^{18}$

Before the description of epithelioid trophoblastic tumor, it is conceivable that some uterine epithelioid trophoblastic tumors were misinterpreted as placental site trophoblastic tumors. In comparison with placental site trophoblastic tumor, epithelioid trophoblastic tumor has been seen in a much higher percentage of women who were peri- or postmenopausal. Histologically, in contrast to a diffuse permeation of myometrial smooth muscle in placental site trophoblastic tumor, a nodular growth pattern with a sharp tumor border is the feature of epithelioid trophoblastic tumor. In addition, infiltrating cords of tumor cells, especially with central hyalinization, also point to the diagnosis of epithelioid trophoblastic tumor. Immunohistochemical staining for hPL is generally positive in individual cells in epithelioid trophoblastic tumor as compared with a diffuse staining in placental site trophoblastic tumor. Recent observations have suggested that a positive immunostaining of p63 protein is highly specific to epithelioid trophoblastic tumor, ${ }^{19}$ in contrast to an absence of the staining in placental site trophoblastic tumor cells. Two of our cases were initially interpreted as placental site trophoblastic tumors. One diagnosis was made before the recognition of epithelioid trophoblastic tumor and one was diagnosed as placental site trophoblastic tumor with comments on the epithelioid features of the tumor. Both tumors were reviewed and reversed as epithelioid trophoblastic tumors based on their epithelioid features and the diffuse nuclear staining of p63. It

Table 2 Differential diagnosis of epithelioid trophoblastic tumor vs squamous cell carcinoma

\begin{tabular}{lll}
\hline Clinicopathologic parameters & Epithelioid trophoblastic tumor & Squamous cell carcinoma \\
\hline Presentation & $\begin{array}{l}\text { Young patient with vaginal bleeding and recent } \\
\text { pregnancy }\end{array}$ & $\begin{array}{l}\text { Older patient with history of HPV infection and/ } \\
\text { or cervical dysplasia }\end{array}$ \\
$\begin{array}{l}\text { Serum hCG } \\
\text { Cervical intraepithelial neoplasia } \\
\text { Histology }\end{array}$ & $\begin{array}{l}\text { Unassociated } \\
\text { Nodular proliferation with hyalinizing changes }\end{array}$ & $\begin{array}{l}\text { Usually present } \\
\text { Squamous carcinoma nests with true keratin } \\
\text { formation }\end{array}$ \\
Cytology & $\begin{array}{l}\text { Polygonal cells with convoluted nuclei and } \\
\text { abundant clear to eosinophilic cytoplasm }\end{array}$ & $\begin{array}{l}\text { Tumor cells at various stages of squamous } \\
\text { differentiation including cell bridges }\end{array}$ \\
Decidualized stromal cells & Frequently present & $\begin{array}{l}\text { Absent, unless with concurrent or recent } \\
\text { pregnancy }\end{array}$ \\
Immunohistochemistry & Tumor cells positive for inhibin, HLA-G, CK18, & $\begin{array}{l}\text { Tumor cells negative for inhibin, HLA-G, CK18, } \\
\text { hPL and hCG } \\
\text { hPL and hCG } \\
\text { Clinical follow-up after }\end{array}$ \\
hysterectomy & $<25 \%$ recurrence rate & Aggressive clinical course depending on the \\
tumor stage
\end{tabular}


should be noted that p63 expression does not help to separate an epithelioid trophoblastic tumor from other lesions of the cervix, including squamous cell carcinoma and squamous dysplasia. ${ }^{20}$

Other differential diagnoses include poorly differentiated endometrioid carcinoma and benign placental site nodule or plaque. In a patient with uterine tumor, clinical elevation of serum hCG may be attributed to a poorly differentiated (endometrioid) carcinoma with focal syncytiotrophoblastic cell differentiation. Particularly in a biopsy specimen, the distinction from an epithelioid trophoblastic tumor can be difficult. An appropriate panel of immunohistochemical markers, including HLA-G, CK18 and inhibin- $\alpha$, may be necessary. Almost always an incidental finding, placental site nodule or plaque is related to a prior pregnancy and consists of nodular persistence of intermediate trophoblasts that show degeneration. The lesion can form and persists long time (as long as 9 years) following a pregnancy. The size of placental site nodule is small (usually less than $1 \mathrm{~cm}$ ) and, in most of the cases, microscopic. It has been proposed that placental site trophoblastic nodules are benign counterpart of epithelioid trophoblastic tumor based on histological and immunohistochemical studies. ${ }^{4}$ Indeed, when Young et $a 1^{21,22}$ described the placental site nodule, they emphasized that it could mimic microinvasive carcinoma. Nevertheless, the microscopic size, lesser cellularity, noninvasive growth and low proliferative index (Ki-67 <10\%) should allow for a confident histological diagnosis of placental site nodule. ${ }^{4}$ When the initial presentation of the tumor is at sites other than uterus, many other neoplasms almost certainly come to consideration first. An erroneous diagnosis as epithelioid mesothelioma in the initial bladder wall biopsy in our case 5 sufficiently exemplifies this difficult situation, even in the presence of an elevated hCG in the patient.

The prognosis of epithelioid trophoblastic tumor appears similar to that of placental site trophoblastic tumor with metastasis and death in 25 and $10 \%$ of patients, respectively. ${ }^{4}$ Although our case number is small, pathological features such as tumor sizes, percentage of tumor necrosis and cytological atypia appear not related to the prognosis, except mitotic activity. The only patient who died of the metastatic disease (case 3) had an average 48 mitotic figures per 10 high-power fields and a Ki-67 labeling index of $86 \%$. High mitotic index has been suspected to be associated with malignant behavior of epithelioid trophoblastic tumor. ${ }^{8}$ One patient in our study (case 5) presented with multiple pelvic and pulmonary metastases. However, the mitotic index in this tumor is 3 per 10 high-power fields. Since the patient had received three cycles of chemotherapy before the hysterectomy, the mitotic count may not represent that of the untreated tumor.

Although the pathogenesis is largely unknown, trophoblastic origin of epithelioid trophoblastic tumor was established based on its morphologic and immunophenotypic similarity to the putative 'chorionic-type' intermediate trophoblasts, ${ }^{2}$ in contrast to that of placental site trophoblastic tumor, a neoplastic proliferation of the intermediate trophoblasts at the implantation site. ${ }^{4}$ This separation appears supported by recent immunohistochemical studies. ${ }^{18,19}$ Confirmation of a fetal origin was recently reported by PCR analysis of 14 cases of epithelioid trophoblastic tumor. $^{23}$ Comparative genomic hybridization study of three of our cases showed no evidence of chromosomal gain or loss (P Hui, unpublished data). Additional molecular and genetic studies of epithelioid trophoblastic tumor are necessary to better understand the pathobiology of this tumor.

In summary, with uncanny histological features of epithelioid trophoblastic tumor to simulate invasive squamous carcinoma and cervical intraepithelial neoplasia when involving the cervix, an interpretation of epithelioid trophoblastic tumor as epithelial neoplasia is likely to continue with undue index of suspicion. Since the prognosis and treatment of epithelioid trophoblastic tumor are drastically different from those of a squamous cell carcinoma, a correct diagnosis is of paramount clinical relevance. An awareness of the clinical presentation with elevated serum hCG, the characteristic histological features of epithelioid trophoblastic tumor and a panel of immunohistochemical markers are helpful in reaching a correct diagnosis of this uncommon, yet distinct trophoblastic tumor.

\section{References}

1 Genest DR, Berkowitz RS, Fisher RA, et al. Gestational trophoblastic disease. In: Tavassoli FA, Devilee P (eds). World Health Organization Classification of Tumours. Pathology and Genetics of Tumours of the Breast and Female Genital Organs. IARC Press: Lyon, 2003, pp 250-254.

2 Shih IM, Kurman RJ. Epithelioid trophoblastic tumor: a neoplasm distinct from choriocarcinoma and placental site trophoblastic tumor simulating carcinoma. Am J Surg Pathol 1998;22:1393-1403.

3 Lage JM, Minamiguchi S, Richardson MS. Gestational trophoblastic diseases: update on new immunohistochemical findings. Curr Diagn Pathol 2003;9:1-10.

4 Shih IM, Kurman RJ. The pathology of intermediate trophoblastic tumors and tumor-like lesions. Int J Gynecol Pathol 2001;20:31-47.

5 Mazur MT, Kurman RJ. Gestational trophoblastic disease. In: Kurman RJ (ed). Blaustein's Pathology of the Female Genital Tract, 4th edn. New York: Springer, 1994, pp 1049-1093.

6 Silva EG, Tornos C, Lage J, et al. Multiple nodules of intermediate trophoblast following hydatidiform moles. Int J Gynecol Pathol 1993;12:324-332.

7 Bouchet-Mishellany F, Ledoux-Pilon A, Darcha C, et al. Trophoblastic gestational disease: a placental site trophoblastic tumor and an epithelioid trophoblastic tumor. Ann Pathol 2004;24:167-171. 
8 Coulson LE, Kong CS, Zaloudek C. Epithelioid trophoblastic tumor of the uterus in a postmenopausal woman. A case report and review of the literature. Am J Surg Pathol 2000;24:1558-1562.

9 Hamazaki S, Nakamoto S, Okino T, et al. Epithelioid trophoblastic tumor: morphological and immunohistochemical study of three lung lesions. Hum Pathol 1999;30:1321-1327.

10 Kamoi S, Ohaki Y, Mori O, et al. epithelioid trophoblastic tumor of the uterus: cytological and immunohistochemical observation of a case. Pathol Int 2002;52:75-81.

11 Knox S, Brooks SE, Wong-You-Cheong J, et al. Choriocarcinoma and epithelioid trophoblastic tumor: successful treatment of relapse with hysterectomy and high dose chemotherapy and peripheral stem cell support: a case report. Gynecol Oncol 2002;85:204-208.

12 Kuo KT, Chen MJ, Lin MC. Epithelioid trophoblastic tumor of the broad ligament. A case report and review of the literature. Am J Surg Pathol 2004;28:405-409.

13 Meydanli MM, Kucukali T, Usubutun A, et al. Epithelioid trophoblastic tumor of the endocervix: a case report. Gynecol Oncol 2002;87:219-222.

14 Narita F, Takeuchi K, Hamana S, et al. Epithelioid trophoblastic tumor (ETT) initially interpreted as cervical cancer. Int J Gynecol Cancer 2003;13:551-554.

15 Ohira S, Yamazaki T, Hatano $\mathrm{H}$, et al. Epithelioid trophoblastic tumor metastatic to the vagina: an immunohistochemical and ultrastructural study. Int J Gynecol Pathol 2000;19:381-386.
16 Parker A, Lee V, Dalrymple C, et al. Epithelioid trophoblastic tumour: report of a case in the fallopian tube. Pathology 2003;35:136-140.

17 Shen DH, Khoo US, Ngan HYS, et al. Coexisting epithelioid trophoblastic tumor and choriocarcinoma of the uterus following a chemoresistant hydatidiform mole. Arch Pathol Lab Med 2004;127:291-293.

18 Singer G, Kurman RJ, McMaster MT, et al. HLA-G immunoreactivity is specific for intermediate trophoblast in gestational trophoblastic disease and can serve as a useful marker in differential diagnosis. Am J Surg Pathol 2002;26:914-920.

19 Shih IM, Kurman RJ. P63 expression is useful in the distinction of epithelioid trophoblastic and placental site trophoblastic tumors by profiling trophoblastic subpopulations. Am J Surg Pathol 2004;28:1177-1183.

20 Cho NH, Kim YB, Park TK, et al. P63 and EGFR as prognostic predictors in stage IIB radiation-treated cervical squamous cell carcinoma. Gynecol Oncol 2003;91:346-353.

21 Young RH, Kurman RJ, Scully RE. Placental site nodules and plaques. A clinicopathologic analysis of 20 cases. Am J Surg Pathol 1990;14:1001-1009.

22 Young RH, Kurman RJ, Scully RE. Proliferations and tumors of intermediate trophoblast of the placental site. Semin Diagn Pathol 1988;5:223-237.

23 Oldt III RJ, Kurman RJ, Shih IM. Molecular genetic analysis of placental site trophoblastic tumors and epithelioid trophoblastic tumors confirms their trophoblastic origin. Am J Pathol 2002;161:1033-1037. 